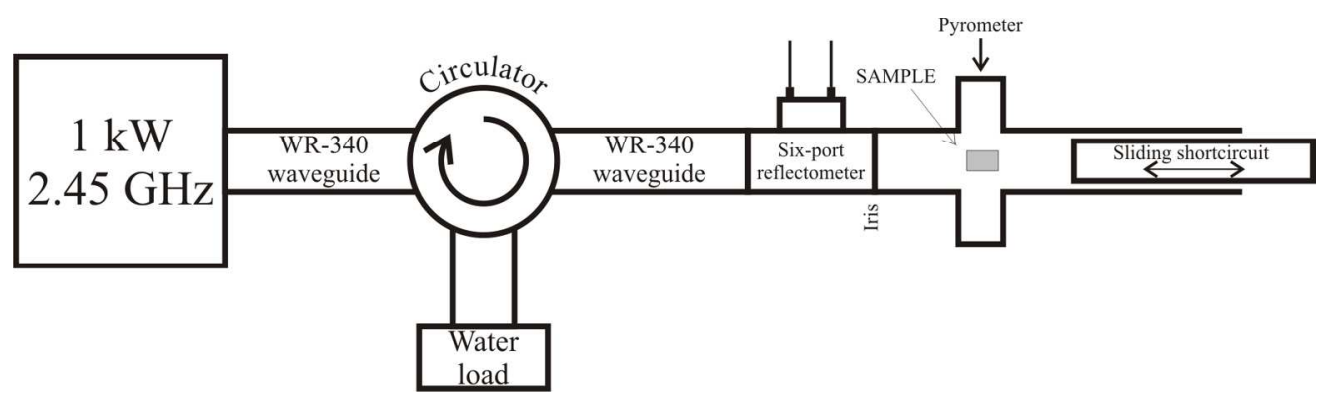

Figure 1. Microwave system setup. $157 \times 45 \mathrm{~mm}(300 \times 300$ DPI $)$ 
Figure 2. Variation of the final relative density vs. maximum temperature for microwave (MW) and conventional sintering (CS) sintered materials. $85 \times 51 \mathrm{~mm}(300 \times 300$ DPI $)$ 

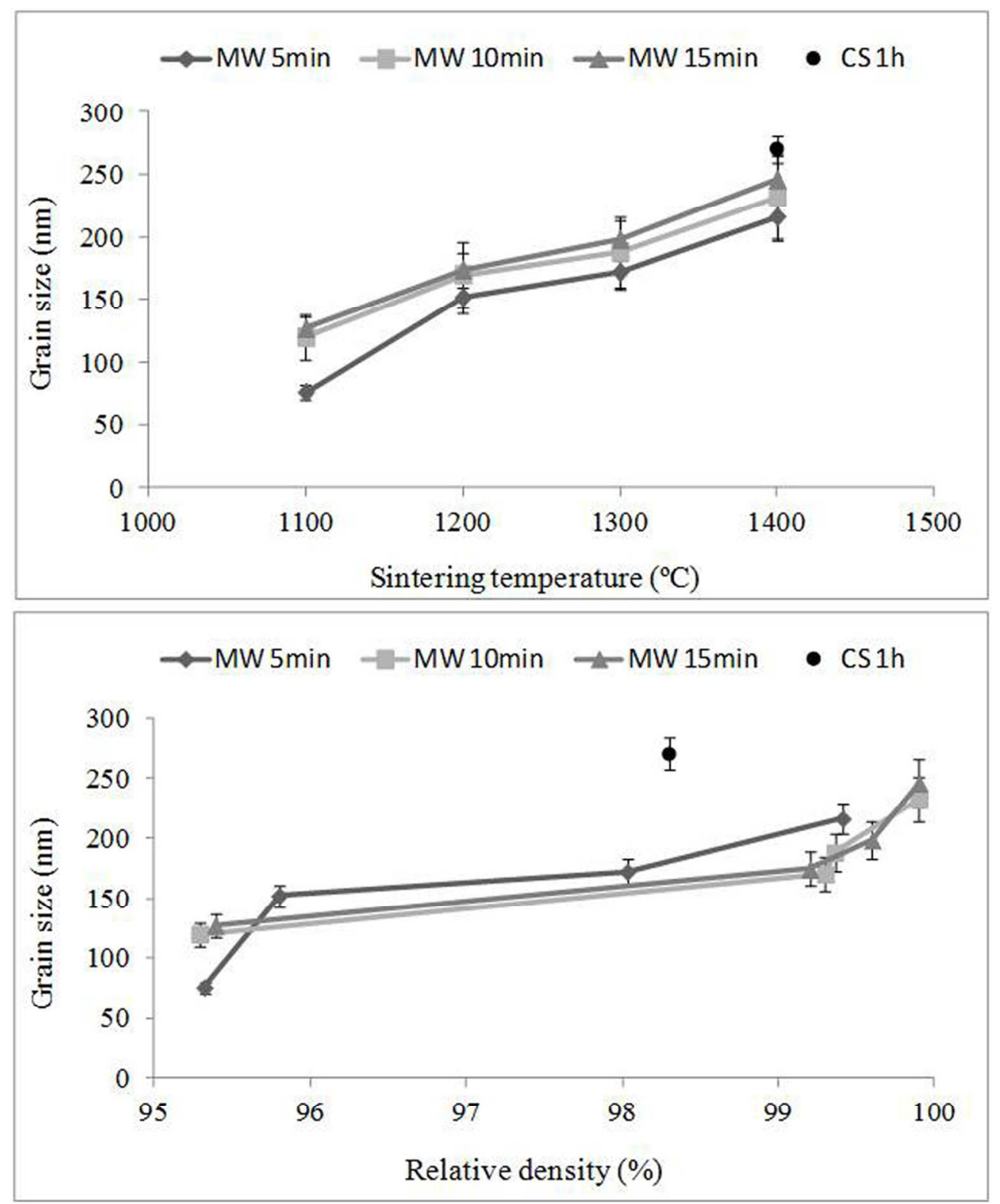

Figure 3. The grain size variations of MW and CS samples as a function of final temperature and grain size versus relative density of nanocrystalline $3 \mathrm{~mol} \%$ yttria-stabilized zirconia (3Y-TZP) after conventional (with a heating rate of $5^{\circ} \mathrm{C}$ min-1) and microwave (with a heating rate of $25^{\circ} \mathrm{C}$ min-1) sintering. $107 \times 131 \mathrm{~mm}(300 \times 300 \mathrm{DPI})$ 

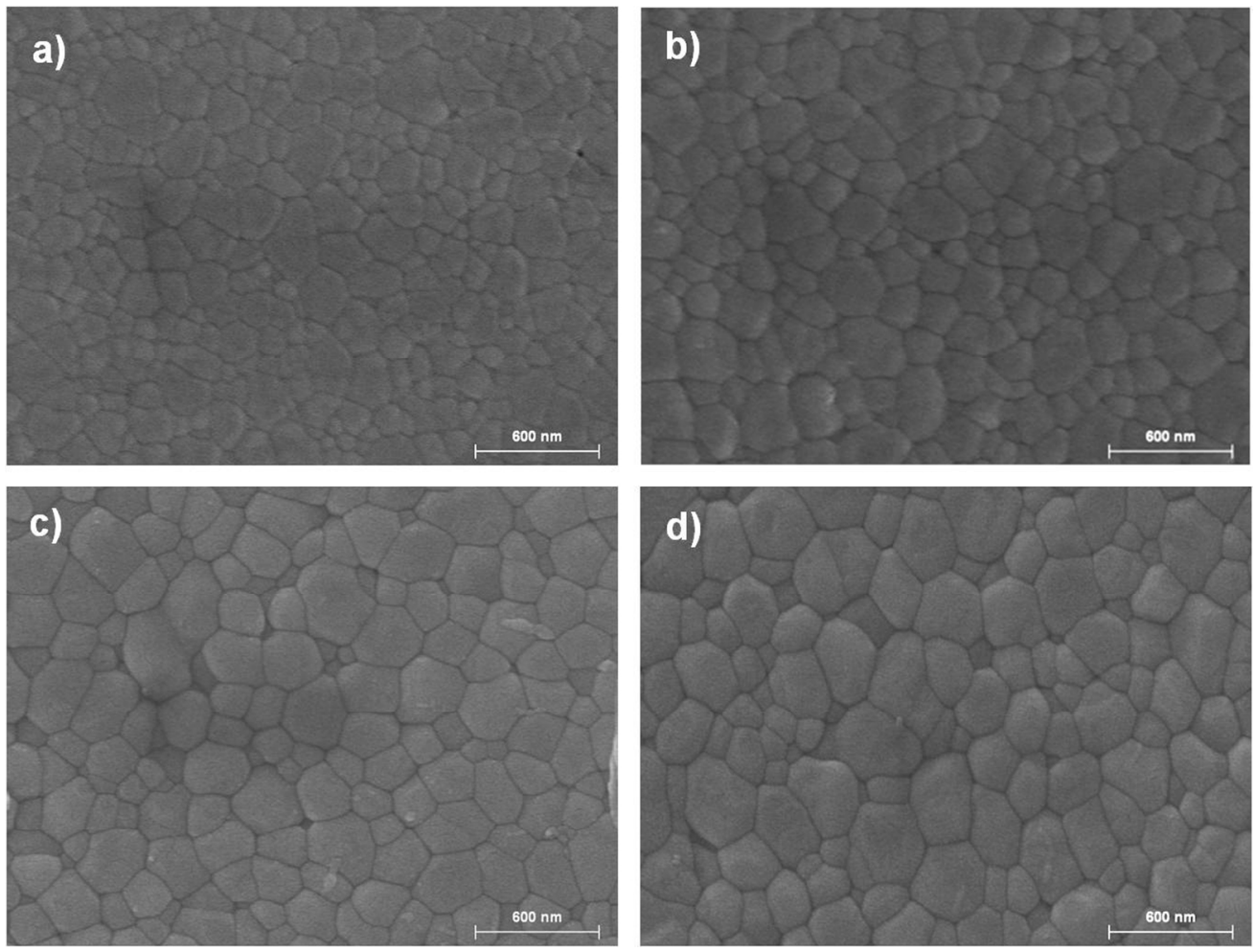

Figure 4. The FE-SEM micrographs of nearly full dense specimens sintered by $\mathrm{MW}$ at $1200^{\circ} \mathrm{C} / 10 \mathrm{~min}$ (a), $1300^{\circ} \mathrm{C} / 10 \mathrm{~min}(\mathrm{~b}), 1400^{\circ} \mathrm{C} / 10 \mathrm{~min}(\mathrm{c})$ and $\mathrm{CS}$ at $1400^{\circ} \mathrm{C} / 60 \mathrm{~min}(\mathrm{~d})$. $170 \times 128 \mathrm{~mm}(300 \times 300 \mathrm{DPI})$ 
Figure 5. Influence of sintering temperature on Vickers hardness of microwave and conventionally fabricated 3Y-TZP materials. $85 \times 51 \mathrm{~mm}(300 \times 300 \mathrm{DPI})$ 
Figure 6. Influence of sintering temperature on fracture toughness of microwave and conventionally fabricated 3Y-TZP materials. $85 \times 51 \mathrm{~mm}(300 \times 300$ DPI $)$ 


\title{
Microwave sintering of zirconia materials: Mechanical and
}

\section{microstructural properties}

\author{
Amparo Borrell ${ }^{1}$, María Dolores Salvador ${ }^{2}$, Felipe L. Peñaranda-Foix ${ }^{3}$, Jose \\ Manuel Cátala-Civera ${ }^{3}$ \\ ${ }^{1}$ Centro de Investigación en Nanomateriales y Nanotecnología (CINN) (Consejo \\ Superior de Investigaciones Científicas - Universidad de Oviedo - Principado de \\ Asturias), Parque Tecnológico de Asturias, 33428 Llanera (Asturias), Spain \\ ${ }^{2}$ Instituto de Tecnología de Materiales (ITM), Universidad Politécnica de Valencia, \\ Camino de Vera, s/n, 46022 Valencia, Spain \\ ${ }^{3}$ Instituto de Aplicaciones de las Tecnologías de la Información y de las \\ Comunicaciones Avanzadas (ITACA), Universidad Politécnica de Valencia, Camino de \\ Vera, s/n, 46022 Valencia, Spain \\ *Corresponding author. Address: Centro de Investigación en Nanomateriales y Nanotecnología \\ (CINN), Parque Tecnológico de Asturias, 33428 Llanera (Asturias), Spain. Tel.: +34985980 \\ 058; Fax: +34 985265 574. E-mail address: a.borrell@cinn.es (A. Borrell).
}

\begin{abstract}
Commercially $3 \mathrm{~mol} \% \mathrm{Y}_{2} \mathrm{O}_{3}$-stabilized tetragonal zirconia $(70-90 \mathrm{~nm})$ compacts were fabricated using a conventional and a non-conventional sintering technique; microwave heating in a resonant mono-mode cavity at $2.45 \mathrm{GHz}$, at temperatures in the $1100-1400$ ${ }^{\circ} \mathrm{C}$ range. A considerable difference in the densification behaviour between conventional (CS) and microwave (MW) sintered materials was observed. The MW


materials attain a full density of $99.9 \%$ of the theoretical density (t.d.) at $1400^{\circ} \mathrm{C} / 10 \mathrm{~min}$, while the CS reach only $98.0 \%$ t.d. at same temperature and $1 \mathrm{~h}$ of dwelling time. Therefore, the MW materials exhibit superior Vickers hardness values (16.0 GPa) when compared with CS (13.4 GPa).

Keywords: Microwave sintering; Grain size; Microstructure; Mechanical properties; $\mathrm{ZrO}_{2}$

\section{INTRODUCTION}

Due to the excellent properties of the Yttria-stabilized Tetragonal Zirconia Polycrystalline (Y-TZP) ceramic materials, such as low thermal conductivity, excellent biocompatibility, high fracture toughness and strength, high crack resistance and low wear rates are widely used for many applications [1], as solid oxide fuel cells, thermal barrier coatings and medical devices, among others. However the densification of nanostructured materials to near to theoretical density is difficult because of the strong tendency to agglomerate and the spontaneous grain growth occurring during sintering process [2,3]. Applying a promising sintering procedure is, therefore, of a great importance for the superior performance of zirconia bodies. Conventional sintering techniques (hot pressing, sinter forging, hot isostatic pressing, etc.) and nonconventional sintering techniques (spark plasma sintering and microwave) represent an alternative approach to the densification of nanoparticles. In ceramic materials, the high temperatures required to fully densify ceramic powders result in large grain sizes due to Ostwald ripening when traditional sintering techniques are used. This makes it extremely difficult to obtain dense materials with nanometric and sub-micrometric grain sizes [4]. To overcome the problem of grain growth, microwave sintering has been 
proposed in this work with an efficient technique for hindering the grain growth as well as producing a homogenous microstructure.

Spark plasma sintering (SPS) is another known sintering technique suitable for the rapid consolidation of a variety of ceramic materials in a short sintering duration [5]. Some authors use this method for the fabrication of large sample of Y-TZP materials by using nanocrystalline zirconia powders [6-7].

Microwave radiation for sintering of ceramic components has recently appeared as a newly focused scientific approach [8-15]. In recent years, microwave heating has been well employed in the field of sintering and joining of ceramics as a result of its advantages against conventional sintering. Microwave sintering has several advantages such as rapid end volumetric heating, improved production rate, enhancement in densification and grain growth prohibition of ceramics [16-19], and most importantly is that possible obtained directly Y-TZP materials without any carbon contamination. This supposes a significant advantage compared to the SPS rapid method. Microwave heating of dielectric materials, such as ceramics, results from the absorption by molecular vibration (rotating electric dipole/dipole reorientation), and ionic conduction of a portion of the energy transported by an oscillating electric field [11]. A genuine "microwave effect", i.e. the acceleration of diffusion mechanisms by the oscillating electric field, was also proposed by some authors to explain the enhancement of the sintering process $[15,20,21]$.

Nightingale et al. [20], for instance, studied the influence of microwave heating on densification and grain growth of 3 mol.\% yttria zirconia samples and then compared them to those samples subjected to the conventional sintering. Microwave heating was found to improve densification processes during the constant rate heating. Comparing to 
the conventionally sintered samples, they observed a kind of shift for the sintering path of microwave-sintered specimens in the direction of increased density for the values of less than $96 \%$ of theoretical density (TD).

Binner et al. [2] have studied the processing of 3 mol.\% yttria partially stabilised zirconia nanopowder into components via slip casting low viscosity but high solids content nanosuspensions and subsequent pressureless sintering via one and two stage sintering involving both pure conventional heating and hybrid conventional-microwave heating. The materials achieved $>99 \%$ of theoretical density using a two stage sintering technique whilst retaining a final average grain size of $<100 \mathrm{~nm}$. When a hybrid microwave conventional approach was used, the resulting average grain size was finer; the best sample to date had a value of just $64 \mathrm{~nm}$ whilst being $\sim 99.5 \%$ dense. It is believed that the primary advantage offered by the hybrid heating approach is the ability to use a much faster initial heating rate.

Mazaheri et al. $[8,16]$ have studied the effect of the conformation method (dry pressing and slip casting) as well as sintering technique (conventional, two-step (TSS) and microwave-assisted sintering with two different heating rates, lower rate (LMS) and high rate (HMS)) on the densification and grain growth of nanocrystalline 8 mol.\% YSZ nanopowder. Nearly full dense bodies with a grain size of $\sim 300 \mathrm{~nm}$ were obtained with TSS, while fast densification via HMS resulted in a fully dense sample with an average grain size of $\sim 0.9 \mu \mathrm{m}$, compared to CS $(2.14 \mu \mathrm{m})$ and LMS $(2.35 \mu \mathrm{m})$ procedures. The authors claim that the reason may be the homogenous microstructure resulting from the fast firing process.

The present work has, on one hand, aimed at exploring the general effect of microwave heating on the sintering procedure of nanocrystalline $3 \mathrm{Y}-\mathrm{TZP}$ and, on the other hand, at revealing the major contribution of high heating rates on the microstructural 
improvement and the mechanical properties of microwave-sintered samples. A rectangular mono-mode cavity at $2.45 \mathrm{GHz}$ equiped with an optical pyrometer was used. This device and its susceptor have been custom-designed and fabricated ad-doc for this study by microwave sintering of various kinds of ceramic powders. A comparison with conventional sintering is also presented.

\section{EXPERIMENTAL PROCEDURE}

\subsection{Microwave sintering}

The microwave setup consists of a microwave source of $1 \mathrm{~kW}$ at $2.45 \mathrm{GHz}$ connected to a mono-mode rectangular cavity (Figure 1). This resonant cavity is coupled by an iris which dimensions are optimized for this application. Between the cavity and the microwave power source there is a circulator with a water load to prevent high power reflections that can damage the source. And there is a six port reflectometer to measure the incident and reflected powers. This measurement system will allow the user to tune or detune the cavity in order to couple more or less power to follow the heating profile previously stated.

The method to tune and detune the cavity consists of a sliding short circuit that can be moved electronically, depending on the reflected and consumed power and on the material temperature. The sample temperature is measured with a pyrometer through a circular hole (which fundamental $\mathrm{TE}_{11}$ mode cut-off frequency is above the working frequency to avoid leakage) located on the top of the cavity.

During heating by this microwave, the distance between the iris and the specimen was set to $180 \mathrm{~mm}$. In each test, a heating rate was controlled to $25^{\circ} \mathrm{C} \mathrm{min}-1$ and applied 
from room temperature to the sintering temperature by adjusting the position of the movable reflector between $100-800 \mathrm{~W}$ of power. The cooling stage was also controlled to $50{ }^{\circ} \mathrm{C} \mathrm{min}^{-1}$. The maximum temperatures reached were $1100{ }^{\circ} \mathrm{C}, 1200{ }^{\circ} \mathrm{C}, 1300{ }^{\circ} \mathrm{C}$ and $1400{ }^{\circ} \mathrm{C}$ with a 5, 10 and 15 -min of dwelling time at the maximum temperature. From room temperature to $600{ }^{\circ} \mathrm{C}$, the specimen remained cooler than the $\mathrm{SiC}$ susceptor due to its poorer dielectric properties (smaller loss tangent) at low temperature. Therefore, zirconia was mainly heated by thermal radiance from the susceptor. Above $600{ }^{\circ} \mathrm{C}$, the specimen became hotter than the susceptor; its temperature followed more or less the prescribed thermal cycle from $600{ }^{\circ} \mathrm{C}$ to $1000{ }^{\circ} \mathrm{C}$ whereas the temperature of the susceptor remained approximately constant at $600{ }^{\circ} \mathrm{C}$. Thus, the compact was heated by both radiance from the susceptor and by coupling with the microwaves (hybrid heating). The dissipated power varied in the $150-250 \mathrm{~W}$ range. Above $1000{ }^{\circ} \mathrm{C}$, the dissipated power sharply increased to $800 \mathrm{~W}$ and the temperature reached $1400{ }^{\circ} \mathrm{C}$ at the upper surface of the zirconia specimen. The control of the heating rate was well controlled and overheating was avoided. This is due to the control of the our microwave apparatus together with the design of the susceptor, which avoid to the strong changes in dielectric properties of zirconia between $400{ }^{\circ} \mathrm{C}$ and $1000{ }^{\circ} \mathrm{C}$. The cooling rate of the microwave-heated samples was controlled by reducing the amount of power supplied to the controller. As a result, the samples were exposed to the microwave field during part of the cooling process, as well as during heating. By slightly prolonging the exposure to the microwave field, any microwave effects might have been slightly increased, but the possibility that this would be significant is unlikely. The effect of temperature on grain growth and densification is much greater.

2.2. Powder characterization and mechanical properties 
The raw material used in this study was commercial $\mathrm{ZrO}_{2}$ (3Y-TZP-B) nanopowders (Tosoh Corp., Japan) with average particle size of (50-60) nm. Green samples were prepared by uniaxial pressing at $200 \mathrm{MPa}$ of pressure in a steel cylindrical die $(2.5 \mathrm{~mm}$ thick, $10 \mathrm{~mm} \phi$ ). The green density was approximately $2.9 \mathrm{~g} \mathrm{~cm}^{-3}$, i.e. $49 \%$ of theoretical density $\left(6.08 \mathrm{~g} \mathrm{~cm}^{-3}\right)$. Ten samples were tested for each property measured. Before sintering, the binder was burned out under air in an electric furnace by heating at $5{ }^{\circ} \mathrm{C} \min ^{-1}$ up to $600{ }^{\circ} \mathrm{C}$ and by soaking for $3 \mathrm{~h}$. The weight loss and shrinkage were about $0.5 \%$ and $20 \%$, respectively. This preliminary debinding stage is necessary, since we observed cracks development during microwave heating for other specimens. This is due to a very heterogeneous temperature distribution, as already mentioned by Janney et al. [22]. Green samples were sintered by hybrid microwave heating, previously described setup, by $\mathrm{SiC}$ susceptor-assisted in the form of cylinders where the temperature was measured with an optical pyrometer (Optris GmbH, Germany) and by conventional heating in a vertical dilatometer (Thermolyne type 46100). Conventional sintering samples was carried out to $1400{ }^{\circ} \mathrm{C}$ using the heating rate of $5{ }^{\circ} \mathrm{C} \mathrm{min}{ }^{-1}$ with 1 $\mathrm{h}$ of holding time at the maximum temperature.

The bulk density of the sintered samples was measured by Archimedes' principle by immersing the sample into a water based liquid. Vickers hardness and fracture toughness assessments were carried out using the indentation method. Sintered samples were longitudinally cut in half cylinders with a diamond saw. The samples were previously polished (Struers, model RotoPol-31) with diamond to $1 \mu \mathrm{m}$ roughness. The hardness of the materials was determined using the indentation technique (Buehler, model Micromet 5103) with a conventional diamond pyramid indenter. The diagonals of each indentation were measured using an optical microscope. Measuring conditions 
for the Vickers hardness, $H_{v}$, were an applying load of $5 \mathrm{~N}$ for $10 \mathrm{~s}$ and the standard specification ASTM E92-72. The value of $H_{v}$ is the relationship between applied load $P$ and the surface area of the diagonals of indentation [23].

To estimate the indentation fracture toughness $K_{I C}, 306 \mathrm{~N}$ Vickers indentations were performed on the surface of the samples, inducing Palmqvist cracks, from which the indentation fracture toughness was obtained by the method of Niihara [24]:

$K_{I C}=0.0298 H a^{1 / 2}\left(\frac{E}{H}\right)^{1 / 2}\left(\frac{c}{a}\right)^{-1.38}$

where $a$ is the half-length of the resultant indentation, $c$ is the total crack length at the surface, $H$ is the Vickers hardness and $E$ is the Young's modulus (typically $220 \mathrm{GPa}$ for $3 \mathrm{Y}-\mathrm{TZP})$.

In order to investigate sample microstructure, polished sections were thermally etched between $30 \mathrm{~min}$ in an electrical furnace under air $100^{\circ} \mathrm{C}$ below their maximum sintering temperature to reveal their microstructure. These sections have been observed using a field emission scanning electron microscope (FEG-SEM, S4100 HITACHI). The grain size of the sintered samples was determined by multiplying the average linear intercept by 1.56 [25]. For each specimen, at least 15 lines were taken, and their average was reported.

\section{RESULTS AND DISCUSSION}

\subsection{Final density and Microstructure}

The final relative density of the specimens sintered by the microwave (MW) and conventional (CS) processes is presented in Figure 2, as a function of their maximum 
sintering temperature. The most-significant factors affecting the density of samples in microwave heating were final temperature, as expected.

Concerning the results of microwave sintering, the first significant outcome of Figure 2 is that the density of a microwave-sintered material is larger than the density of a material conventionally sintered at the same measured temperature. The conventional test reached the relative density of $98.3 \%$ at $1400^{\circ} \mathrm{C}$.

The final density of the microwave-sintered materials at different dwelling times increased sharply from 5 and $10-15 \mathrm{~min}$, especially at $1200{ }^{\circ} \mathrm{C}$, where the relative densities of 5 and $10 \mathrm{~min}$ are $95.8 \%$ and $99.3 \%$, respectively. It can be seen that at 1400 ${ }^{\circ} \mathrm{C}$ all of the samples sintered by MW show very similar densities ( $\left.>99.4 \%\right)$. More importantly, it shows that relative densities of $95-99 \%$ may be obtained without any crack.

Fully dense specimens were, therefore, obtained at significantly lower sintering times by MW. In other words, while the sintering time required to achieve relative densities above $>98 \%$ is 350 min using CS, the MW leads to the similar dense specimens in only $40 \mathrm{~min}$. It is important to note that the final economic cost is very significant.

The relative density difference between the CS and MW samples are attributed to the different styles by which the samples are heated. The heating in CS corresponds to the conduction rule in which the surface of the material is heated sooner than the core. According to the surface heating in CS, the heat should penetrate from the surface of the material in to the bulk by the well-known conduction phenomenon. The heat conduction from the surface to the core, however, requires the time and such a trend can somehow delay the activation of densification mechanisms such as the thermally activated ones. 
Microwave heating, on the other hand, is generated by the molecular or ionic interactions with an electromagnetic field via conversions of electromagnetic energy into thermal energy [26,27]. The heat is, thus produced in the whole bulk of the material at the same time and the activation of densification mechanisms are in need of much shorter times. Microwave sintering is, therefore, capable of providing denser specimens within the shorter sintering times compared to conventional sintering at the same heating rate.

The average grain size of $3 \mathrm{Y}-\mathrm{TZP}$ specimens sintered through microwave and conventional heating is displayed in Figure 3, as a function of final temperature. It can be seen that the grain growth is linear with sintering temperature. As indicated in Figure 3, all sintered samples have a similar grain size. Small differences in MW process are shown as the dwelling time increases $(5-15 \mathrm{~min})$. The average grain size of the specimen sintered at $1100{ }^{\circ} \mathrm{C}-5$ and 15 min by MW reaches about 76 and $127 \mathrm{~nm}$, respectively. While samples sintered at $1400^{\circ} \mathrm{C}-5$ and 15 min yields a grain size of 216 and $246 \mathrm{~nm}$, respectively. The average grain size of the conventionally sintered specimen is about $270 \mathrm{~nm}$ at an identical temperature. Therefore, the graph indicates that the main parameter governing grain growth is the maximum sintering temperature. Moreover, these data show similar grain sizes in conventionally and microwave-sintered materials with high density suggesting that the microwaves had no direct effect on cation segregation at the grain boundaries during the phase partitioning process, which is known to be responsible for the sluggish grain growth during the final stage of sintering [28].

The higher heating rate used in MW results in grain refining, as can be seen from Figure 3. Also, the faster heating through this method postpones access to the activation energy 
required for grain boundary mobility. Consequently, a remarkable amount of absorbed energy during microwave heating is consumed for densification and not grain coarsening, as seen in Figure 3, where it is shown that a shorter sintering time as well as fast heating led to an increase of densification rate to grain growth rate. Therefore, the MW sample reaches the final grain size, with fully dense specimens, to the smaller values.

To summaries despite the fact that the results of the final grain size of both methods, MW and CS, are very similar, the long heating-cooling time CS ( $\sim 10 \mathrm{~h})$ front MW (40 min), sets important advantages on the industrial application of this method as an advanced process for new technological challenges.

The microstructure of the sintered materials has been observed by FE-SEM in longitudinal sections along the axis of the cylindrical samples. The conventionalsintered specimens exhibit a bimodal microstructure made of equiaxed grains with an average size of $270 \mathrm{~nm}$ at $1400{ }^{\circ} \mathrm{C}-1 \mathrm{~h}$ (Figure $4 \mathrm{~d}$ ). In the specimens sintered by microwave heating at 1200,1300 and $1400{ }^{\circ} \mathrm{C}-10$ min (Figures $4 \mathrm{a}, 4 \mathrm{~b}$ and $4 \mathrm{c}$, respectively), the microstructure can be considered as homogeneous in the whole sample. For example, in the sample sintered at $1400{ }^{\circ} \mathrm{C}$ (Figure $4 \mathrm{c}$ ), the average grain size is $228 \mathrm{~nm}$ in the upper zone, $232 \mathrm{~nm}$ in the central and $235 \mathrm{~nm}$ in the bottom zone. Application of a heating microwave method has provided traces of improvement for the grain growth suppression in comparison with CS.

The microwave device designed for this work with specific parameters enables the obtaining of materials with very high densities and, most importantly, a fully homogeneous microstructure. An important concept to consider in the MW designer is 
the position of the system to measure the temperature of the sample. In our case, the necessary calculations have been made for the temperature measured by the optical pyrometer is exactly the same temperature as the specimen. Therefore, this shows that the temperature measured on the specimen top surface is representative of the bulk temperature.

\subsection{Hardness and fracture toughness}

Vickers hardness and fracture toughness of microwave and conventionally fabricated 3Y-TZP materials are presented in Figures 5 and 6 as a function of sintering temperature. The experimental measurements show that the hardness values increase with the density data.

As indicated by the Figure 5, the highest level of hardness belonged to the specimens sintered by the MW method. In the CS sample at $1400{ }^{\circ} \mathrm{C}$, the values are close to the sample by MW sintering with 15 min of dwelling time ( 13.7 GPa). The maximum hardness achievement is for the sample sintered by $\mathrm{MW}$ at $1400{ }^{\circ} \mathrm{C} / 10 \mathrm{~min}, 16.0 \mathrm{GPa}$. This is an excellent value compared with earlier studies on MW-sintered 3Y-TZP that reported a hardness of 14.5 $\mathrm{GPa}$ [10], 11.3 GPa [29] and 8.3 GPa [30]. In summary, at $1400{ }^{\circ} \mathrm{C}$, the hardness values of the MW-sintered materials are higher than those of the conventionally fabricated materials at same temperature with $1 \mathrm{~h}$ of dwelling time. This is due to better and faster densification of the MW-sintered specimens.

The fracture toughness of MW-sintered specimens with 10 and $15 \mathrm{~min}$ of dwelling time decreased slightly, with increasing sintering temperature. On the contrary, the fracture 
toughness values of samples sintered with 5 min of dwelling time increased with the final temperature.

The results show that the hardness of sintered samples has a strong dependence on grain size. On the contrary, the results of the fracture toughness of sintered samples do not show strong dependence on grain size. As shown in Figure 6, the fracture toughness values decreased from 4.43 for the MW sample sintered at $1100{ }^{\circ} \mathrm{C} / 10 \mathrm{~min}$ up to 4.01 $\mathrm{MPa} \mathrm{m}^{1 / 2}$ for $1400{ }^{\circ} \mathrm{C} / 10 \mathrm{~min}$, and values of samples sintered by $\mathrm{MW}$ with $5 \mathrm{~min}$ increased slightly. The CS sample showed a high value of fracture toughness (4.48 MPa $\mathrm{m}^{1 / 2}$ ), the same as $\mathrm{MW}$ sintered samples at $1400{ }^{\circ} \mathrm{C} / 5 \mathrm{~min}$. For $\mathrm{CS}$ samples, this behaviour can be attributed, on the one hand, the heating mode and the other hand the refining of microstructure, which is a well-known method for enhancing the mechanical properties of Y-TZP bodies [31]. The heating mode may cause a lower thermal stresses in the sintered material and this can help to not crack propagate. Therefore, we can conclude that can be obtained CS materials with grain size slightly larger than MW and similar fracture toughness values.

\section{CONCLUSIONS}

Sintering behaviour of $3 \mathrm{~mol} \%$ TZP-B nanopowder compacts is investigated in the current study using conventional and microwave-assisted sintering designed ad-hoc specifically for this investigation.

This device included an optical pyrometer with an emissivity perfectly calibrated for measuring the temperature of the top surface of the zirconia materials. Using this device we achieved a fine control of the heating rate, final temperature and holding time. In these experiments with a susceptor-assisted and controlled heating rate, the temperature of the compact surpasses the temperature of the susceptor above $600{ }^{\circ} \mathrm{C}$ without any 
crack, which proved that the heating of the hybrid type is correct to obtain materials as desired. These hybrid microwave sintering experiments provided a homogeneous microstructure specimens with a larger density compared to the specimen conventionally sintered at the same temperature. Concerning microstructure changes, our results proved that the grain size was only dependent on the maximum sintering temperature, whatever the heating mode. However, due to the positive effect of microwaves on the densification, a microwave heated specimen showed a slightly smaller grain size when compared to the grain size achieved by conventional heating. Microwave sintered 3Y-TZP materials exhibited superior hardness values when compared with conventional fired materials, as was expected from their higher densities. On the contrary, the fine microstructure of the specimens produced by CS $(270 \mathrm{~nm})$, makes the value of fracture toughness similar to those achieved by MW.

\section{Acknowledgments}

This work has been carried out with programme to support research and development of the Polytechnic University of Valencia (U.P.V) under multidisciplinary projects PAID05-09 and PAID-05-10. A. Borrell, acknowledges the Spanish Ministry of Science and Innovation for her FPI Ph.D. grant and the people from Institute Technological of Materials (ITM) of the U.P.V for helping us with the microwave experiments during a stay in 2010-2011. Felipe L. Peñaranda-Foix wants to thank the Generalitat Valenciana for the grant obtained in the frame of the Program BEST/2010, because some results of this paper have been possible with this help.

\section{REFERENCES}


1. S. Deville, L. Gremillard, J. Chevalier and G. Fantozzi, "A critical comparison of methods for the determination of the aging sensitivity in biomedical grade yttriastabilized zirconia,” J. Biomed. Mater. Res. B. Appl. Biomater., 72 [2] 239-245 (2005).

2. J. Binner, K. Annapoorani, A. Paul, I. Santacruz and B. Vaidhyanathan, "Dense nanostructured zirconia by two stage conventional/hybrid microwave sintering," J. Eur. Ceram. Soc., 28 [5] 973-977 (2008).

3. G. D. Zhan and A. K. Mukherjee, "Processing and characterization of nanoceramic composites with interesting structural and functional properties," Rev. Adv. Mater. Sci., 10 [3] 185-196 (2005).

4. U. Anselmi-Tamburini, J. E. Garay and Z. A. Munir, "Fast low-temperature consolidation of bulk nanometric-ceramic materials," Scripta Mater., 54 [5] 823-828 (2006).

5. M. I. Mendelson, "Average grain size in polycrystalline ceramics,” J. Am. Ceram. Soc., 52 [8] 443-446 (1969).

6. X. J. Chen, K. A. Khor, S. H. Chan and L. G. Yu, "Overcoming the effect of contaminant in solid oxide fuel cell (SOFC) electrolyte: spark plasma sintering (SPS) of 0.5 wt.\% silica-doped yttria-stabilized zirconia (YSZ),” Mater. Sci. Eng. A. 374 [1-2] 64-71 (2004).

7. M. Trunec, K. Maca and Z. Shen, "Warm pressing of zirconia nanoparticles by the spark plasma sintering technique," Scripta Mater., 59 [1] 23-26 (2008).

8. M. Mazaheri, Z. Razavi Hesabi, F. Golestani-Fard, S. Mollazadeh, S. Jafari and S. K. Sadrnezhaad, "The effect of conformation method and sintering technique on the densification and grain growth of nanocrystalline $8 \mathrm{~mol} \%$ yttria-stabilized zirconia," J. Am. Ceram. Soc., 92 [5] 990-995 (2009). 
9. A. Goldstein, N. Travitzky, A. Singurindy and M. Kravchik, "Direct microwave sintering of yttria-stabilized zirconia at 2.45 GHz,” J. Eur. Ceram. Soc., 19 [12] 20672072 (1999).

10. P. Both and N. Lequeux, "Do microwaves increase the sinterability of ceramics?," Solid State Ionics 101-103 [2] 1229-1233 (1997).

11. D. D. Upadhaya, A. Ghosh, K. R. Gurumurthy and R. Prasad, "Microwave sintering of cubic zirconia," Ceram. Int., 27 [4] 415-418 (2001).

12. M. Mizuno, S. Obata, S. Takayama, S. Ito, N. Kato, T. Hiraia and M. Sato, "Sintering of alumina by $2.45 \mathrm{GHz}$ microwave heating," J. Eur. Ceram. Soc., 24 [2] 387-391 (2004).

13. Ch. Kuo, Ch. Chen and I. Lin, "Microstructure and nonlinear properties of microwave sintered $\mathrm{ZnO}-\mathrm{V}_{2} \mathrm{O}_{5}$ varistors: I, Effect of $\mathrm{V}_{2} \mathrm{O}_{5}$ doping," J. Am. Ceram. Soc., 81 [11] 2942-2948 (1998).

14. L. Cong, X. Zheng, P. Hu and S. Dan-feng, " $\mathrm{Bi}_{2} \mathrm{O}_{3}$ vaporization in microwavesintered ZnO varistors,” J. Am. Ceram. Soc., 90 [9] 2791-2794 (2007).

15. J. Wang, J. Binner, B. Vaidhyanathan, N. Joomun, J. Kilner, G. Dimitrakis and T. E. Cross, "Evidence for the microwave effect during hybrid sintering," J. Am. Ceram. Soc., 89 [6] 1977-1984 (2006).

16. M. Mazaheri, A. M. Zahedi and M. M. Hejazi, "Processing of nanocrystalline 8 mol\% yttria-stabilized zirconia by conventional, microwave-assisted and two-step sintering," Mater. Sci. Eng. A 492 261-267 (2008).

17. T. Ebadzadeh and M. Valefi, "Microwave-assisted sintering of zircon," J. Alloys Comp., 448 [1-2] 246-249 (2008). 
18. C. García-Gañan, J. J. Meléndez-Martínez, D. Gómez-García and A. DomínguezRodríguez, "Microwave sintering of nanocrystalline Ytzp (3 Mol\%),” J. Mater. Sci., 41 [16] 5231-5234 (2006).

19. J. Cheng, D. Agrawal, Y. Zhang and R. Roy, "Microwave sintering of transparent alumina," Mater. Lett., 56 [4] 587-592 (2002).

20. S. A. Nightingale, D. P. Dunne and H. K. Worner, "Sintering and grain growth of 3 mol\% yttria zirconia in a microwave field," J. Mater. Sci., 31 [19] 5039-5043 (1996).

21. S. A. Nightingale, H. K. Worner and D. P. Dunne, "Microstructural development during the microwave sintering of yttria-zirconia ceramics," J. Am. Ceram. Soc., 80 [2] 394-400 (1997).

22. M. A. Janney, C. L. Calhoun and H. D. Kimrey, "Microwave sintering of oxide fuel cell materials. I, zirconia-8 mol\% yttria,” J. Am. Ceram. Soc., 75 [2] 341-346 (1992).

23. G. Antis, P. Chantikul, B. Lawn and D. Marshall, "A Critical evaluation of indentation techniques for measuring fracture toughness: I, Direct crack measurements," J. Am. Ceram. Soc., 64 [9] 533-538 (1981).

24. K. Niihara, R. Morena and D. P. H. Hasselman, "Evaluation of $\mathrm{K}_{\mathrm{IC}}$ of brittle solids by the indentation method with low crack-to-indentation ratios," J. Mater. Sci. Lett., 1 13-16 (1982).

25. Y. Wang and Z. Fu, "Study of temperature field in spark plasma sintering," Mater. Sci. Eng. B., 90 [1-2] 34-37 (2002).

26. D. Acierno, A. A. Barba and M. d'Amore, "Heat transfer phenomena during processing materials with microwave energy," Heat Mass. Trans., 40 [5] 413-420 (2004).

27. E. T. Thostenson and T. W. Chou, "Microwave processing: fundamentals and applications," Compos. Part. A., 30 [9] 1055-1071 (1999). 
28. K. Matsui, H. Yoshida and Y. Ikuhara, "Isothermal sintering effects on phase separation and grain growth in yttria-stabilized tetragonal zirconia polycrystal," J. Am. Ceram. Soc., 92 [2] 467-475 (2009).

29. J. Wilson and S. M. Kunz, "Microwave sintering of partially stabilized zirconia," J. Am. Ceram. Soc., 71 [1] 40-41 (1988).

30. D. D. Upadhyaya, A. Ghosh, G. K. Dey, R. Prasad and A. K. Suri, "Microwave sintering of zirconia ceramics,” J. Mater. Sci., 36 [19] 4707-4710 (2001).

31. A. J. A. Winnubst, K. Keizer and A. J. Burggraaf, "Mechanical properties and fracture behaviour of $\mathrm{ZrO}_{2}-\mathrm{Y}_{2} \mathrm{O}_{3}$ ceramics," J. Mater. Sci., 18 [7] 1958-1966 (1983). 
1

2

3

4

5

6

7

8

9

10

11

12

13

14

15

16

17

18

19

20

21

22

23

24

25

26

27

28

29

30

31

32

33

34

35

36

37

38

39

40

41

42

43

44

45

46

47

48

49

50

51

52

53

54

55

56

57

58

59

60

\section{Figure Captions}

Figure 1. Microwave system setup.

Figure 2. Variation of the final relative density vs. maximum temperature for microwave (MW) and conventional sintering (CS) sintered materials.

Figure 3. The grain size variations of MW and CS samples as a function of final temperature and grain size versus relative density of nanocrystalline $3 \mathrm{~mol} \%$ yttriastabilized zirconia (3Y-TZP) after conventional (with a heating rate of $5^{\circ} \mathrm{C} \mathrm{min}^{-1}$ ) and microwave (with a heating rate of $25^{\circ} \mathrm{C} \mathrm{min}^{-1}$ ) sintering.

Figure 4. The FE-SEM micrographs of nearly full dense specimens sintered by MW at $1200^{\circ} \mathrm{C} / 10 \mathrm{~min}(\mathrm{a}), 1300^{\circ} \mathrm{C} / 10 \mathrm{~min}(\mathrm{~b}), 1400^{\circ} \mathrm{C} / 10 \mathrm{~min}(\mathrm{c})$ and $\mathrm{CS}$ at $1400^{\circ} \mathrm{C} / 60 \mathrm{~min}(\mathrm{~d})$.

Figure 5. Influence of sintering temperature on Vickers hardness of microwave and conventionally fabricated 3Y-TZP materials.

Figure 6. Influence of sintering temperature on fracture toughness of microwave and conventionally fabricated 3Y-TZP materials. 